\title{
DEVELOPMENT OF A RISK MANAGEMENT SYSTEM FOR THE PROJECT LIFE CYCLE OF SUPER-HIGHRISE RESIDENCE
}

\author{
Shuzo Furusaka, Makoto Ohsaki, Kazunori \\ Harada, Sohsuke Arai, Motohiko Yokose \\ Dept. of Architecture and architectural Engineering \\ Kyoto University \\ Cluster C, Kyoto University, Katsura Campus, Nishikyo-ku, \\ Kyoto,615-8540,Japan \\ Hideki Kashii, Katsuki Nakazono \\ Condominium division \\ SEIWA REAL ESTATE CO., Ltd. \\ $4^{\text {th }}$ floor, SN bldg.,5-6-4,Nishi tenma, Kita-ku, \\ Osaka,530-0047,Japan
}

\author{
Takashi Kaneta \\ International Innovation Center \\ Kyoto University \\ International Innovation Center, Kyoto University, \\ Kyoto University Rohm Plaza, Nishikyo-ku, \\ Kyoto, 615-8520, Japan \\ Norikazu Katoh \\ General manager \\ AQA Co, Ltd \\ $10^{\text {th }}$ floor, Ginsen bldg.,3-10-19, Minami Senba, Chuo-ku, \\ Osaka,542-0081,Japan
}

\begin{abstract}
In a super-highrise residence project, the project manager needs to forge a long-term risk management plan which covers any problems which may occur from the beginning of the project to the time of demolition. Development of a system which supports a risk strategy effectively is needed as a project becomes more complex. In this paper, first, through analysis of the life cycle of a specific super-highrise residency project, risk phenomena are specified from the viewpoint of each party, and a database which has various kinds of information about the inherent risks, is developed. Next, a mathematical model is formulated based on the comparison of optimal strategy against a risk, elucidated quantitatively within a fixed risk strategy budget. Finally, a system which has these functions is developed and improved upon through analyzing the results of practical experimentation.
\end{abstract}

Keywords: Risk management, Super-highrise residence, Project life cycle, Project management

\section{BACKGROUND}

1.1 Background and purpose of the research

In construction projects, long-term risk management is necessary which considers weather, labor force, and financial conditions. In addition to construction itself, environmental aspects and demolition problems shall have to be considered. Super-highrise residency projects have more risks to consider because of long construction schedules and the many claims made after occupation.

However, available knowledge is limited to manage the risks which incorporate the perspectives of all parties involved multi-laterally over the life cycle of a project beginning with planning, followed by construction, occupation and finally demolition. Previous studies deal mainly with risks from in a qualitative manner rather than quantitatively [1-5]. Thus, a risk management framework has not theoretically been established yet. Therefore, this study focuses on the following aspects.

1) To illustrate, a specific construction project is surveyed. Throughout its life cycle, characteristics and details of risks are then identified.

2) Identified risks are compiled in a database to manage them effectively.

3) A methodology is developed to manage specified risks quantitatively and a mathematical model is developed to support decision-making to select an optimal combination of strategies within a fixed risk strategy budget.

4) The system which has these functions is developed and improved based on practical experimentation.

\subsection{Research system}

This research is performed under an academic-industrial alliance. Not only the management researcher but also the structure and the facility personnel join the academic research team. In addition, the client and the construction manager join the joint research team. Other parties such as the architect or the general contractor join as collaborators in the survey of the actual project. The research system is shown in Figure 1.

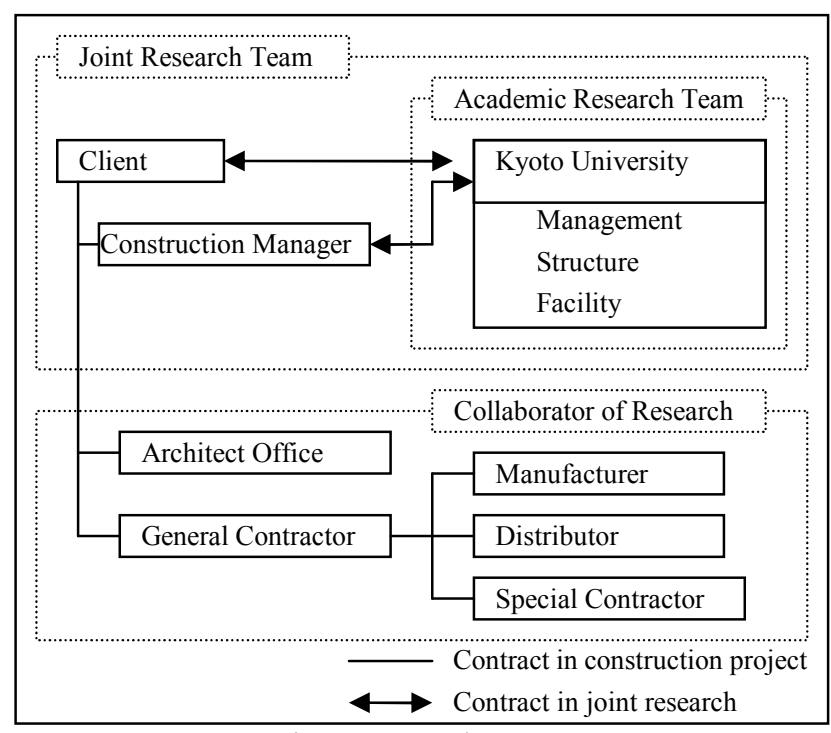

Fig1. Research system 


\section{DEVELOPMENT OF METHOD OF RISK QUANTIFICATION}

2.1 Risk structuring

In this study, in order to develop the method of quantitative and qualitative risk analysis, the risk model, shown in Figure 2 , is developed by combining methods of fault tree analysis (FTA) and the method based on event tree analysis (ETA). The following events exist in this model.

(1) Top event

This kind of event directly causes risk events in a chain of the events within the risk model.

(2) Failure cause

This event is a minimal unit when the top events are broken down by FTA format.

(3) Failure mode

These events are formed in the formation of FTA.

(4) Derivative risk event

These events are caused by top events, and entail damage to the projects. Parts between a top event and the derivative risk event, and between a derivative risk event and the next derivative risk event are called "chain arrows".

(5) Project environment

There are events in which their occurrence is determined by the environment of the particular project. In this study, project environments correspond to any of the following.

1) Conditions totally unrelated to the parties' decision making pertaining to the project.

2) Decision making which has the potential to lead to damage and profit together.

3) Decision making which includes clients whom can influence the whole of the project.

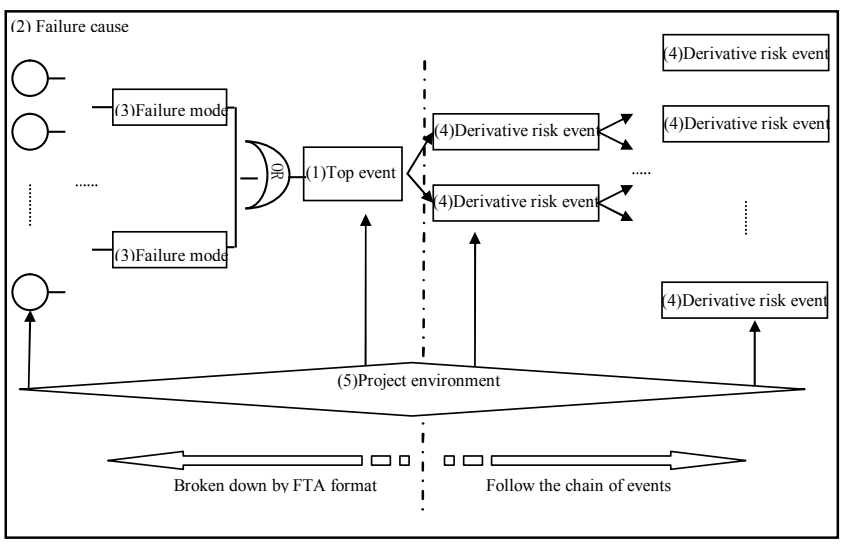

Fig2. Risk model

\subsection{Risk quantification}

In the risk model, the structured risks are quantified. In the quantification process, probability measurements and impact measurements are adopted. In this study, expected values of the derivative risk events equate the measure of the risks. Each derivative risk event has an undesirable outcome which is called a "risk result". Risk results are classified into 8 categories as; increase of costs, safety problems, quality defects, delay of project, problems occurring after completion, loss of corporate image to society, loss of corporate image to inhabitants, loss of corporate image in project. Each expected value of a derivative risk event is reported as an expected value of a corresponding risk result. The total sum of the expected values represents the project risk. Each event is formulated as follows.

(1) Probability of occurrence of each top event

Probability of occurrence of each risk result $P_{T}$ is calculated by formula (1)

$$
P_{T(i)}=\coprod_{f=1}^{e} \prod_{j \in K_{f}} P_{X(i, j)}
$$

Where, $P_{\mathrm{X}(\mathrm{i}, \mathrm{j})}$ is the probability of occurrence of failure cause $X(i, j), K_{f}$ corresponds with minimum cut-sets, and $e$ denotes the number of minimum cut-sets.

(2) Probability of occurrence of each derivative risk event Probability of occurrence of derivative risk event $Y\left(s_{p-1}, p, s_{p}\right)$ is calculated by formula (2)

$P_{Y\left(s_{p-1}, p, s_{p}\right)}=P_{Y\left(s_{p-2}, p-1, s_{p-1}\right)} \times Q_{Y\left(s_{p-1}, p, s_{p}\right)}$

Where, $Y\left(s_{p-1}, p, s_{p}\right)$ is the $s_{p}{ }^{\text {th }}$ derivative risk event in which the number of chains from the top event is $p$, and chains from $s_{p-1}{ }^{\text {th }}$ derivative risk event in which the number of chains is $p-1, Q_{Y\left(s_{p-1}, p, s_{p}\right)}$ is the probability of the chain arrow from derivative risk event $Y\left(s_{p-2}, p-1, s_{p-1}\right)$ to $Y\left(s_{p-1}, p, s_{p}\right)$.

(3) Expected value of each derivative risk event Expected value of derivative risk event $Y\left(s_{p-1}, p, s_{p}\right)$ is calculated by formula (3)

$E_{\left(s_{p-1}, p, s_{p}\right)}=P_{\left(s_{p-1}, p, s_{p}\right)} \times I_{\left(s_{p-1}, p, s_{p}\right)}$

Where, $I_{Y\left(s_{p-1}, p, s_{p}\right)}$ is the impact of derivative risk event $Y\left(s_{p-1}, p, s_{p}\right)$.

\subsection{Risk strategy}

In the risk model, risk strategies are adopted to particular failure causes and the chain arrows. The following categories are determined for the classification of risk strategy.

(1) Backup plan by insurance

By adopting the insurance against the derivative risk event, the impact of the risk is transferred to the parties outside of the project.

(2) Avoidance by elimination of occurrence conditions

By eliminating the project environment of a particular event, the event itself disappears.

(3) Mitigation by internal effort

By mitigating the probability or impact of the event, the absolute amount of the project risk is decreased.

(4)Allocation

Risk bearers are changed in the project by adopting this kind of strategy. If the risk is managed well, the absolute amount of the project risk is decreased.

The following categories are determined for classifying the relation of risk strategy.

(1) Exclusive strategy

Two or more strategies of this relation can't be adopted simultaneously. 
(2) Priority strategy

The effect of one strategy is only to supplement another. Supplemental strategy can't be adopted independently.

(3) Unified strategy

Two or more strategies of this relation have to be adopted concurrently.

\section{RISK DATABASE}

3.1 Risk survey in an actual project

In a real super-highrise residency project, an on going questionnaire survey was conducted for each corresponding party to identify any potential risks. Next, details were collected concerning the identified risks by interview with persons in charge. As many parties as possible are surveyed, and stages already finished are surveyed by recounting past experiences. Schematics and the range of the survey are shown in Table 1. Items of the survey are shown in Table 2.

Table 1. Subject of the survey

\begin{tabular}{|l|l|l|}
\hline \multicolumn{2}{|l|}{ Subject of the survey } & Super-highrise residence "X" \\
\hline Parties & Client & "A", "B" \\
\cline { 2 - 3 } & Architect, Supervisor & "C" \\
\cline { 2 - 3 } & Contractor & "D" \\
\cline { 2 - 3 } & Construction Manager & "E" \\
\hline Structure & Reinforced concrete (Partly steel) \\
\hline Number of stories & 35 stories above and 1 under \\
\hline Number of houses & 269 houses \\
\hline Term of construction & From Nov. 2003 to Jan. 2006 \\
\hline
\end{tabular}

Table 2. Items of the survey

\begin{tabular}{|c|c|}
\hline Items of the survey & Remarks \\
\hline Controllability & Possible/Impossible \\
\hline Possible timing of occurrence & Free form \\
\hline Who currently owns the risk & Free form \\
\hline Risk result & Choice from the 8 risk results \\
\hline Risk strategy & Free form \\
\hline $\begin{array}{l}\text { Possible timing when the } \\
\text { strategy is adopted }\end{array}$ & Free form \\
\hline Who adopted the strategy & Free form \\
\hline Costs for the strategy & Free form (including labor costs) \\
\hline $\begin{array}{l}\text { Occurrence probability of the } \\
\text { risk } \\
\text { (after the strategy and without } \\
\text { the strategy) }\end{array}$ & $\begin{array}{l}\text { 1. No assumption in the project } \\
2 \text {. There is the possibility of } \\
\text { occurrence, but It seems unlikely that } \\
\text { this risk will actually prevail in the } \\
\text { project. } \\
\text { 3. There is sufficient possibility of } \\
\text { risk occurrence in the project. } \\
\text { 4. The risk will not absolutely occur, } \\
\text { but It seems likely that the risk may } \\
\text { actually occur in the project. } \\
\text { 5. The risk will absolutely occur. }\end{array}$ \\
\hline $\begin{array}{l}\text { Impact of the risk } \\
\text { (after the strategy and without } \\
\text { the strategy) }\end{array}$ & $\begin{array}{l}\text { 1. Up to } 1 \text { million yen. } \\
\text { 2. More than } 1 \text { million yen up to } 10 \\
\text { million yen. } \\
\text { 3. More than } 10 \text { million yen up to } 100 \\
\text { million yen. } \\
\text { 4. More than } 100 \text { million yen up to } 1 \\
\text { billion yen. } \\
\text { 5. More than } 1 \text { billion yen. }\end{array}$ \\
\hline Relation of risk strategy & Free form \\
\hline Remarks & Free form \\
\hline
\end{tabular}

3.2 Development of a risk database

By summarizing the survey results, a database was developed, which can be used to share risk information. Using this method, risk data which are separately gathered by individuals, project teams and enterprises can be summarized. This will lead to better the management of risks to unify a network of shared knowledge, to distinguish standard risk strategies with optional strategies, and to understand correlations between multiple sources of risks. Sharing risk information will be beneficial to establish risk management protocol in similar projects in the future $[4,6]$.

\section{QUANTITATIVE OPTIMIZATION METHOD OF RISK MANAGEMENT STRATEGY}

4.1 Formulation by mathematical programming In order to find an optimal combination of risk strategies within a fixed risk strategy budget, the following items are formulated as an object function or constraint functions by mathematical programming. The optimization problem is reduced to a $0-1$ integer programming problem.

(1)Object function

The object function is the degree of project risk. It is calculated by formula (4)

$$
E=\sum_{i=1}^{n} \sum_{s_{1}=1}^{t_{1}} \ldots \sum_{s_{p}=1}^{t_{p}} \ldots \sum_{s_{q}=1}^{t_{q}} \sum_{p=1}^{q} E_{\left(s_{p-1}, p, s_{p}\right)} \quad\left(s_{0}=i\right)
$$

\section{(2)Constraint functions of events}

- Probability of occurrence of failure causes

Probability of occurrence of failure causes $P_{X(i, j)}$ is calculated by formula (5)

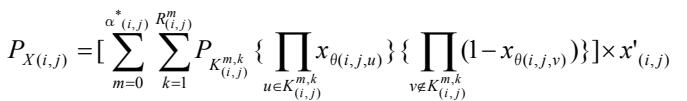

Where, $\alpha_{(i, j)}^{*}$ is the number of the strategies of the failure cause $X(i, j), M_{(i, j)}^{m}$ is the set of the combination of m-plex strategies of $X(i, j), K_{(i, j)}^{m, k}$ is the $k^{\text {th }}$ set in $M_{(i, j)}^{m}, R_{(i, j)}^{m}$ is the number of the set in $M_{(i, j)}^{m}\left(==_{\alpha_{i, j,}} C_{m}\right), P_{K_{(i, j)}^{m, k}}$ is the probability of occurrence of $X(i, j)$ after $K_{(i, j)}^{m, k}$ is adopted, $x_{\theta(i, j, \alpha)}$ is the decision value of the strategy $S_{\theta(i, j, \alpha)}$, either 1 (adoption) or 0 (no adoption), $x_{(i, j)}^{\prime}$ is the decision value of the project environment $X^{\prime}(i, j)$, either 1 (existence) or 0 (no existence).

- Summary of the costs of strategies of failure causes Summary of the costs of strategies of failure causes is calculated by formula (6).

$C_{X(i, j)}=\sum_{\alpha=1}^{\alpha_{(i, j, j)}} c_{\theta(i, j, \alpha)} X_{\theta(i, j, \alpha)}$

Where, $c_{\theta(i, j, \alpha)}$ is the cost of $S_{\theta(i, j, \alpha)}$.

- Probability of occurrence of chain arrows Probability of occurrence of chain arrows is calculated by formula (7). 


$$
\begin{aligned}
Q_{Z\left(s_{p-1}, p, s_{p}\right)}=\left[\sum_{m=0}^{\beta_{\left(s_{p-1}, p, s_{p}\right)}^{*}}\right. & \sum_{k=1}^{R_{\left(s_{p-1}, p, s_{p}\right)}^{m}} Q_{K_{\left(s_{p-1}, p, p, s_{p}\right)}^{m, k}}\left\{\prod_{u \in K_{\left(s_{p-1}, p, s_{p}\right)}^{m, k}} y_{\theta\left(s_{p-1}, p, s_{p}, u\right)}\right\} \\
& \left.\left\{\prod_{v \notin K_{\left(s_{p-1}, p, p, s_{p}\right)}^{m, k}}\left(1-y_{\theta\left(s_{p-1}, p, s_{p}, v\right)}\right)\right\}\right] \times y_{\left(s_{p-1}, p, s_{p}\right)}^{\prime}
\end{aligned}
$$

Where, $\beta_{\left(s_{p-1}, p, s_{p}\right)}^{*}$ is the number of strategies comprising the chain arrow $\mathrm{Z}\left(s_{p-1}, p, s_{p}\right), M_{\left(s_{p-1}, p, s_{p}\right)}^{m}$ is the set of the combination of m-plex strategies of $\mathrm{Z}\left(s_{p-1}, p, s_{p}\right)$ $\left(m \leqq \beta_{\left(s_{p-1}, p, s_{p}\right)}^{*}\right), K_{\left(s_{p-1}, p, s_{p}\right)}^{m, k}$ is the $k^{\text {th }}$ set in $M_{\left(s_{p-1}, p, s_{p}\right)}^{m}, R_{\left(s_{p-1}, p, s_{p}\right)}^{m}$ is the number of the set in $M_{\left(s_{p-1}, p, s_{p}\right)}^{m}\left(=_{\beta_{\left(s_{p-1}, p, s_{p}\right)}^{*}} C_{m}\right), Q_{K_{\left(s_{p-1}^{m}, p, s_{p}\right)}^{m}}$ is the probability of occurrence of $Z\left(s_{p-1}, p, s_{p}\right)$ after $K_{\left(s_{p-1}, p, s_{p}\right)}^{m, k}$ is adopted, $y_{\theta\left(s_{p-1}, p, s_{p}, \beta\right)}$ is the decision value of the strategy $S_{\theta\left(s_{p-1}, p, s_{p}, \beta\right)}$, either 1 (adoption) or 0 (no adoption), $y_{\left(s_{p-1}, p, s_{p}\right)}^{\prime}$ is the decision value of the project environment $\mathrm{Y}^{\prime}\left(s_{p-1}, p, s_{p}\right)$, either 1 (existence) or 0 (no existence).

- Impact of derivative risk events

Impact of derivative risk events is calculated by formula (8).

$$
\begin{aligned}
& I_{Z\left(s_{p-1}, p, s_{p}\right)}=\left[\sum_{m=0}^{\beta^{*}\left(s_{p-1}, p, s_{p}\right.} \sum_{k=1}^{R_{\left(s, p-1, p, s_{p}\right)}^{m}} I_{K_{\left(s_{p-1}, p, s_{p}\right)}^{m, k}}\left\{\prod_{u \in K_{\left(s_{p-1}, p, s_{p}\right)}^{m,}} y_{\theta\left(s_{p-1}, p, s_{p}, u\right)}\right\}\right. \\
& \left.\left\{\prod_{v \in K_{(s, p-1, p, s, p)}}\left(1-y_{\theta\left(s_{p-1}, p, p, s_{p}, v\right)}\right)\right\}\right] \times y_{\left(s_{p-1}, p, s_{p}\right)}^{\prime}
\end{aligned}
$$

Where, $I_{K_{\left(s_{p-1}^{m, p, s}\right)}^{m, k}}$ is the probability of occurrence of $\mathrm{Y}\left(s_{p-1}, p, s_{p}\right)$ after $K_{\left(s_{p-1}, p, s_{p}\right)}^{m, k}$ adopted.

- Summary of the costs of strategies of chain arrows Summary of the costs of strategies of chain arrows is calculated by formula (9).

$\mathrm{C}_{\mathrm{Z}\left(s_{p-1}, p, s_{p}\right)}=\sum_{\beta=1}^{\beta_{\left(s_{p-1}, p, s_{p}\right)}^{*}} c_{\theta\left(s_{p-1}, p, s_{p}, \beta\right)} y_{\theta\left(s_{p-1}, p, s_{p}, \beta\right)}$

Where, $c_{\theta\left(s_{p-1}, p, s_{p}, \beta\right)}$ is the cost of $S_{\theta\left(s_{p-1}, p, s_{p}, \beta\right)}$

(3)Constraint functions of costs

Constraint of cost is calculated by formula (10).

$$
\sum_{i=1}^{n} \sum_{j=1}^{l(i)} \sum_{s_{1}=1}^{t_{1}} \ldots \sum_{s_{p}=1}^{t_{p}} \ldots \sum_{s_{q}=1}^{t_{q}}\left\{C_{X(i, j)}+\sum_{\mathrm{p}=1}^{\mathrm{q}} \mathrm{C}_{\mathrm{Z}\left(s_{p-1}, p, s_{p}\right)}\right\} \leqq C_{\max }
$$

Where, $C_{\max }$ is the fixed risk strategy budget.

(4)Constraint functions of relation of strategies Constraint of relation of risk strategies is calculated by formula (11)-(16)

- Exclusive strategy

$\sum_{s=1}^{r} x_{\theta\left(\mathrm{i}, \mathrm{j}, k_{\mathrm{s}}\right)} \leqq 1$

$\sum_{g=1}^{h} y_{\theta\left(s_{p-1}, p, s_{p}, l_{g}\right)} \leqq 1$

- Priority strategy

$$
\begin{aligned}
& x_{\theta\left(\mathrm{i}, \mathrm{j}, \mathrm{k}_{1}\right)} \geqq \ldots \geqq x_{\theta\left(\mathrm{i}, \mathrm{j}, \mathrm{k}_{\mathrm{s}}\right)} \geqq \ldots \geqq x_{\theta\left(\mathrm{i}, \mathrm{j}, \mathrm{k}_{\mathrm{r}}\right)} \\
& y_{\theta\left(s_{p-1}, p, s_{p}, l_{1}\right)} \geqq \ldots \geqq y_{\theta\left(s_{p-1}, p, s_{p}, l_{g}\right)} \geqq \ldots \geqq y_{\theta\left(s_{p-1}, p, s_{p}, l_{h}\right)}
\end{aligned}
$$

- Unified strategy

$x_{\theta\left(\mathrm{i}, k_{1}\right)}=\ldots=x_{\theta\left(\mathrm{i}, \mathrm{j}, k_{\mathrm{s}}\right)}=\ldots=x_{\theta\left(\mathrm{i}, k_{\mathrm{r}}\right)}$

$y_{\theta\left(s_{p-1}, p, s_{p}, l_{1}\right)}=\ldots=y_{\theta\left(s_{p-1}, p, s_{p}, l_{g}\right)}=\ldots=y_{\theta\left(s_{p-1}, p, s_{p}, l_{h}\right)}$

- Consistency of identical strategies being adopted

When identical strategies exist in different places, their consistency of adoption must be satisfied. Constraint of consistency of adopted identical strategies is calculated by formula (17) and (18).

$$
\begin{aligned}
& x_{\theta\left(i, j, k_{1}\right)}=\ldots= x_{\theta\left(i, j, k_{r}\right)}=y_{\theta\left(s_{p-1}, p, s_{p}, l_{1}\right)}=\ldots=y_{\theta\left(s_{p-1}, p, s_{p}, l_{h}\right)} \\
& x_{\theta\left(i, j, k_{1}\right)}+\ldots+x_{\theta\left(i, j, k_{r}\right)}+y_{\theta\left(s_{p-1}, p, s_{p}, l_{1}\right)}+\ldots+y_{\theta\left(s_{p-1}, p, s_{p}, l_{h}\right)}+(-1)^{0}\left\{x_{\theta\left(i, j, k_{1}\right)}+\ldots+x_{\theta\left(i, j, k_{r}\right)}+y_{\theta\left(s_{p-1}, p, s_{p}, l_{1}\right)}+\ldots+y_{\theta\left(s_{p-1}, p, s_{p}, l_{h}\right\}}\right\} \\
& \\
& \quad-(-1)^{1}\left\{x_{\theta\left(i, j, k_{1}\right)} x_{\theta\left(i, j, k_{2}\right)}+\ldots+y_{\theta\left(s_{p-1}, p, s_{p}, l_{h-1}\right)} y_{\theta\left(s_{p-1}, p, s_{p}, l_{h}\right)}\right\} \\
& \\
& \quad \ldots+(-1)^{n-1}\left\{x_{\theta\left(i, j, k_{1}\right)} x_{\theta\left(i, j, k_{2}\right)} \ldots y_{\theta\left(s_{p-1}, p, s_{p}, l_{h-1}\right)} y_{\theta\left(s_{p-1}, p, s_{p}, l_{h}\right)}\right\}
\end{aligned}
$$

\subsection{Quantitative optimization method}

In the previous study [4], the optimization problem is formulated by branch-and-bound method and enumeration method, and the effectiveness is demonstrated. The system developed in this study is assumed to have an enormous number of valuables followed by an increase in the amount of data in the future. Thus, the optimization method in the system does not necessitate an excessive amount of search time to find an optimal solution, but rather requires an accurate approximate solution to be found quickly. In this study, the optimal solution is searched for using meta-heuristic.

\section{DEVELOPMENT OF A RISK MANAGEMENT SYSTEM}

5.1 Establishment of a risk management system

The risk management system which has both the risk database and the optimization method is actually developed by VBA (Visual Basic for Application). The number of chains of events and the level of breaking down by FTA format from the top events are both set to two. Three failure modes, nine failure causes, three first derivative risk events, and nine second derivative risk events exist per one top event. In the system, the qualitative data such as probability, Impact, and labor costs collected qualitatively in Chapter 3, have to be quantified. The qualitative data of probability and impact is quantified based on the documents [7], shown in Table 3 and 4, in order to be able to respond to any kind of risks. The labor cost of one person per day is set to 30,000 yen based on the $1206^{\text {th }}$ ministerial announcement [8]. An example of database presentation is shown in Figure .3.

Table 3. Subject of the survey

\begin{tabular}{|l|l|}
\hline Data of the survey & Data after quantification \\
\hline 1 & 0.050 \\
\hline 2 & 0.100 \\
\hline 3 & 0.350 \\
\hline 4 & 0.675 \\
\hline 5 & 0.925 \\
\hline
\end{tabular}


Table 4. Subject of the survey

\begin{tabular}{|l|l|}
\hline Data of the survey & Data after quantification \\
\hline 1 & 0.5 million yen \\
\hline 2 & 5 million yen \\
\hline 3 & 50 million yen \\
\hline 4 & 500 million yen \\
\hline 5 & 5 billion yen \\
\hline
\end{tabular}

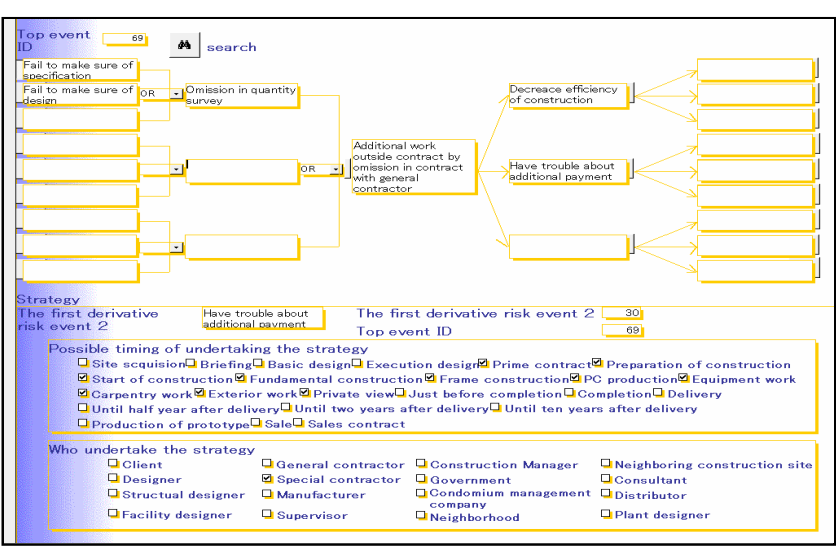

Fig3. An example of database presentation

\subsection{Case study}

As an example, optimization is carried out for all strategies in the database by changing the projected risk strategy budget from 0.5 million yen to 100 million yen. However, for the risks with financial impacts equaling 5 billion yen, the strategies against them have to be adopted preferentially, so they are eliminated to distinguish them from other risks. In this example, the number of strategies (decision valuable) is 203 , but the number of free strategies is 107 . As a result, an optimal combination is selected from 96 strategies.

The results of the optimization are sorted by risk results, shown in Figure 4, and by time series, shown in Figure5. The results from the adoption of decision values in each risk strategy budget are shown in Table5.

In Figure 4, the reduction of the project risk is increased by the addition of the risk strategy budget up to 0.5 million yen, and keeps reducing until 50 million yen, however slightly more than 50 million yen. In this figure, the cost-benefit performance is found by comparing the costs with the reduction of the project risk. In Figure 5, the project risk between preparation of construction and completion are mostly large, and the risks after the completion are second. This is because during construction there are risks that have the potential impact of greatly causing "delay of project", "increase of costs", or "safety problems", and after completion the risks that have the greatest probability are those such as claims. In this figure, after adoption of the free strategies, the risk after completion is reduced. This is because the clients adopt strategies such as to confirm a particular risk with the architects or contributors. When the risk strategy budget is little, the strategies against the risks during construction have priority. These strategies are adopted by contractors during construction, shown in Table 5.

In this manner, the system is effective in that the cost-benefit performance can be found, and useful information is discovered by analyzing the project risk and its reduction by risk results or time series.

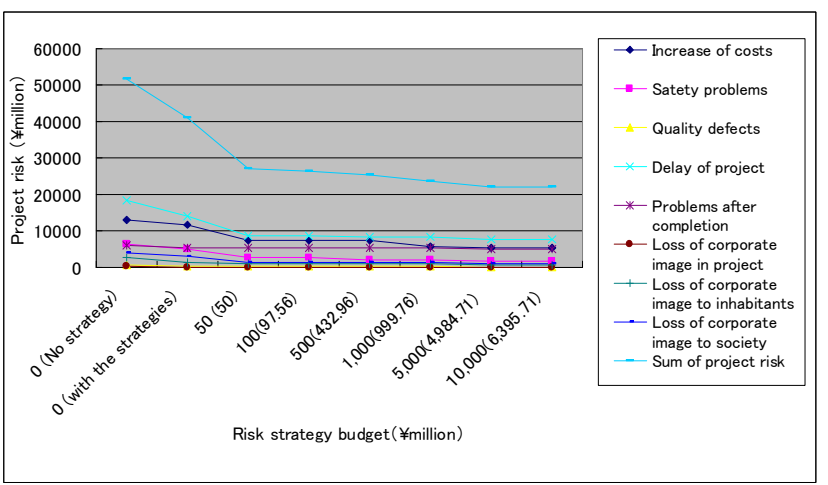

Fig4. The project risk of optimal combination by risk results

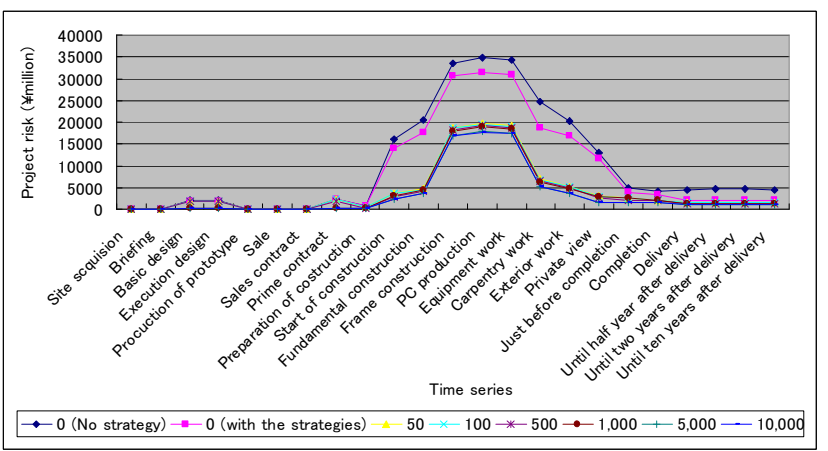

Fig5. The project risk of optimal combination by time series

Table5. The adoption of decision valuables

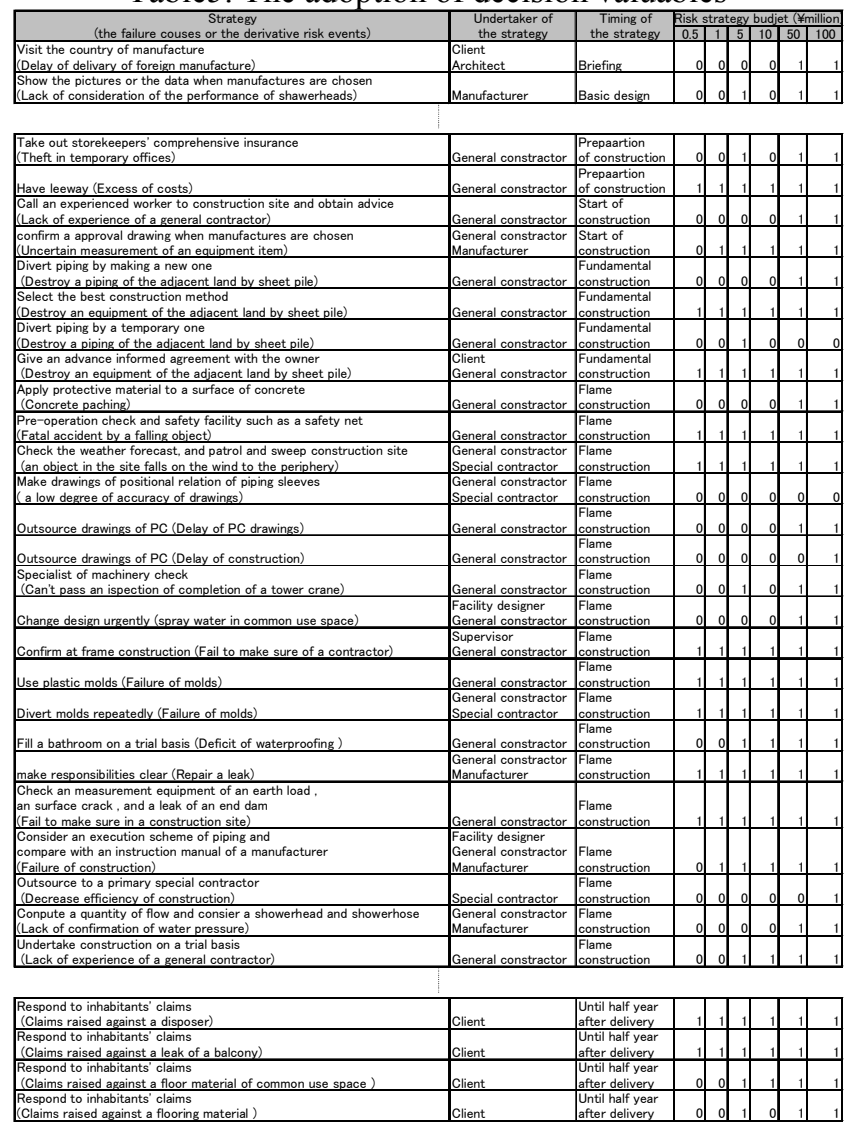




\section{IMPROVEMENT OF PRACTICALITY OF THE SYSTEM THROUGH DEMONSTRATION}

In this study, the function of the system is improved based on the views of the practitioner, and the percentage completion is advanced. Definitively speaking, to examine the effectiveness, the system is applied to another project, and improvement is shown in a presentation to the client and the construction manager. As a result, it is made clear that clients desire to manage all projects involved all at once, they want to be made aware of all risks, and they want to manage risks effectively using different methods at each stage. It is also made clear that construction manager wants to know both the risk and benefit of an applied strategy because they develop the information into value engineering. Based on these results, the system is improved, and new functions are added. The functions of the system within the project are shown in Figure 6.

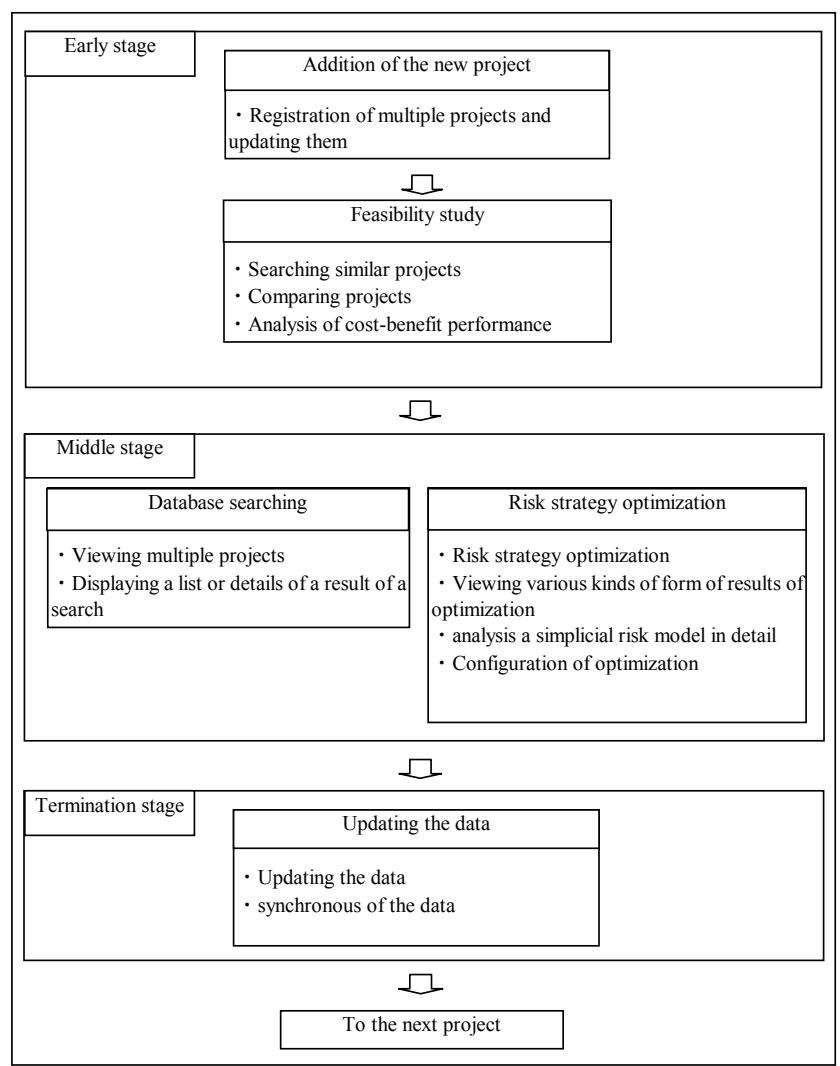

Figure 6 . The functions of the system within the project

\section{CONCLUSION}

In this study, risks were collected in an actual construction project for a super high-rise residential structure, and a database is developed to lead to better management of risks. The risk model is developed, and the method of selecting an optimal combination of strategies within a fixed risk strategy budget is based on the model. Finally, the system which fulfills these functions is developed and improved upon based on the results elucidated through experimenting with strategists. By using this system, practitioners in projects can manage risks effectively and reasonably.

Future considerations for this research would be as follows;
1) By applying this system to other real construction projects to support risk management, the data amount of the system would have to be increased.

2) The system must be improved to enable application in various situations or ordering systems.

3) The system must be improved so that it is able to be applied from the viewpoint of maintainability design and reliability design.

\section{REFERENCES}

[1] Tsung-Chieh Tsai, Shuzo Furusaka, Takashi Kaneta : Development of Risk Analysis Method for Building Projects, Journal of Asian Architecture and Building Engineering, AIJ, Vol. 1 No. 2, pp.157-164, 2002.11

[2] Tsung-Chieh Tsai, Shuzo Furusaka, Takashi Kaneta : Evaluating Risk Factors and Risk Strategies of Procurement System in Construction Project, Proceedings of $15_{\text {th }}$ Symposium on Building Construction and Management of Projects, pp.65-72, 1999.7

[3] Tsung-Chieh Tsai, Shuzo Furusaka, Takashi Kaneta, Takashi Sawada, Hiroshi Kusaka : Development of Decision Support System of Risk Management in Construction Phase of Construction Projects, Proceedings of $17_{\text {th }}$ Symposium on Building Construction and Management of Projects, pp.89-96, 2001.7

[4] Yasuhiro Orita, Shuzo Furusaka, Takashi Kaneta, Kazunori Harada, Makoto Ohsaki, Sohsuke Arai, Motoharu Nakanishi : Quantitative Analysis of the Risk Management of a Super-Highrise Residence, Journal of architecture and planning, AIJ, NO.594, pp.117-124, 2005.8

[5] Sohsuke Arai, Shuzo Furusaka, Takashi Kaneta, Makoto Osaki, Kazunori Harada, Motohiko Yokose, Hideki Kashi, Katsuki Nakazono, Norikazu Katoh : Development of the risk management system for life cycle of a project of a super-highrise residence, Journal of architecture and planning, AIJ, NO.602, pp.151-158, 2006.4

[6] Sohsuke Arai, Shuzo Furusaka, Takashi Kaneta, Makoto Osaki, Kazunori Harada, Motohiko Yokose, Hideki Kashi, Katsuki Nakazono, Motoharu Nakanishi : Development of Database of Risk Management in a Super-Highrise Housing Project, Proceedings of $21_{\mathrm{th}}$ Symposium on Building Construction and Management of Projects, pp.251-256, 2005.7

[7] Alan Cockshaw, Duncan Ferguson, Paul Grace : Risk analysis and management for projects, Institution of civil engineers and the faculty and institute of actuaries , 1998

[8] Former Ministry of Construction (1979) the 1206th ministerial announcement 